\title{
Juvenile fibromatosis of the orbit: a case report with review of the literature
}

\author{
R Jean Campbell, James A Garrity
}

\begin{abstract}
Proliferation of fibrous tissues to form a localised mass with infiltrating margins may occur anywhere in the body; involvement of the orbit is rare. Children and young adults are most commonly affected. The term "juvenile fibromatosis' is one of several synonyms. Of the two main forms of this entity, the solitary form is the more common and the prognosis is good. The multicentric form has a poor prognosis. The patient described, a 21/2-year-old boy, had a solitary nodule of juvenile fibromatosis removed from the right orbit and was asymptomatic $23 / 4$ years postoperatively.
\end{abstract}

Fibroblastic proliferations of the orbit are rare. Fibromatosis is more common in children and must be distinguished from a true malignant neoplasm. The patient described had a slowly progressive superior orbital mass shown by histology and electron microscopy to be juvenile fibromatosis. This entity is locally aggressive but does not metastasise.

\section{Case report}

CLINICAL HISTORY

A 21/2-year-old boy sustained a right 'black eye' as a result of a fall. Over a six-month period right ptosis with inferior displacement of the eye occurred, and a soft mass was palpated in the superior orbit. A soft discoid mass $(6 \times 2 \times 1 \mathrm{~mm})$ was removed by incisional biopsy. The diagnosis was benign haemangioendothelioma.

Six months postoperatively, because of apparent clinical progression, the lesion was injected with $1.0 \mathrm{ml}$ of $50 \%$ dexamethasone $/ 50 \%$ betamethasone. Nine months postoperatively the patient was seen at the Mayo Clinic. On examination his visual acuity was $20 / 80$ right eye and 20/30 left eye. The right globe was proptosed and downwardly displaced (Figs 1 and 2).

At lateral orbitotomy a firm, greyish white mass $(3 \times 2.5 \times 1.5 \mathrm{~cm})$ was removed (Fig 3$)$.

\footnotetext{
Division of Pathology and Department of

Ophthalmology, Mayo

Clinic and Mayo

Foundation, Rochester,

Minnesota, USA

R J Campbell

J A Garrity

Correspondence to:

Dr R J Campbell, Mayo Clinic,

200 First Street SW,

Rochester, MN 55905 USA.

Accepted for publication

13 November 1990
}

Figure 1 The right globe has $6 \mathrm{~mm}$ of proptosis and is downwardly displaced $5 \mathrm{~mm}$. A firm, non-tender, palpable mass was present beneath supraorbital rim. Supraduction in the right eye was severely limited.

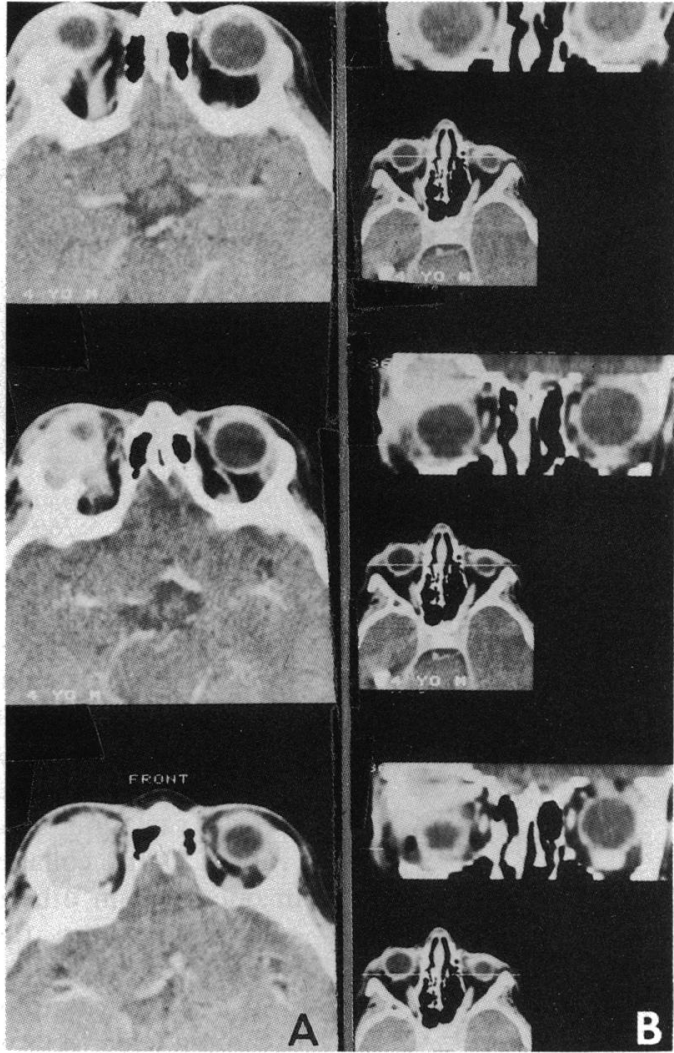

Figure 2 Axial $(A)$ and reformatted coronal $(B)$ computed tomography scans of orbit demonstrate a lobulated, well demarcated, enhancing, soft tissue mass within superior lateral quadrant of right orbit. There is slight retrobulbar extension and downward displacement of globe. Sclerosis and remodelling of orbital roof are noted. (B: Courtesy of the University of Minnesota, Minneapolis, Minnesota.)

\section{PATHOLOGY}

The margins were free of tumour. Tissue was fixed in $2 \%$ glutaraldehyde and $10 \%$ neutral buffered formalin. Staining techniques included haematoxylin-eosin, periodic acid Schiff with

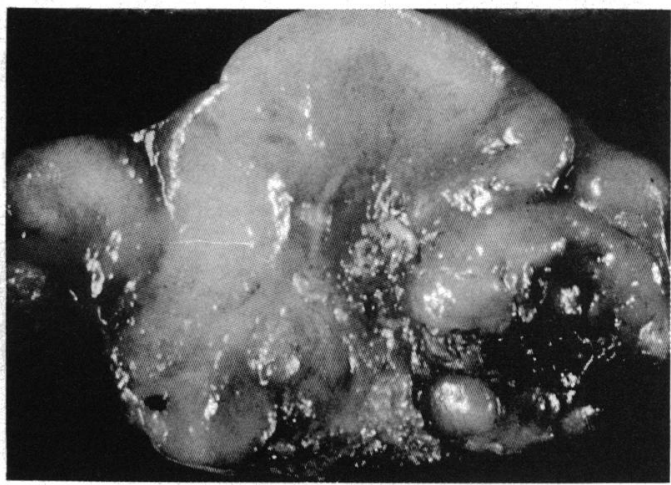

Figure 3 Firm, greyish white mass $(3 \times 2.5 \times 1.5 \mathrm{~cm})$ removed from right orbit. 


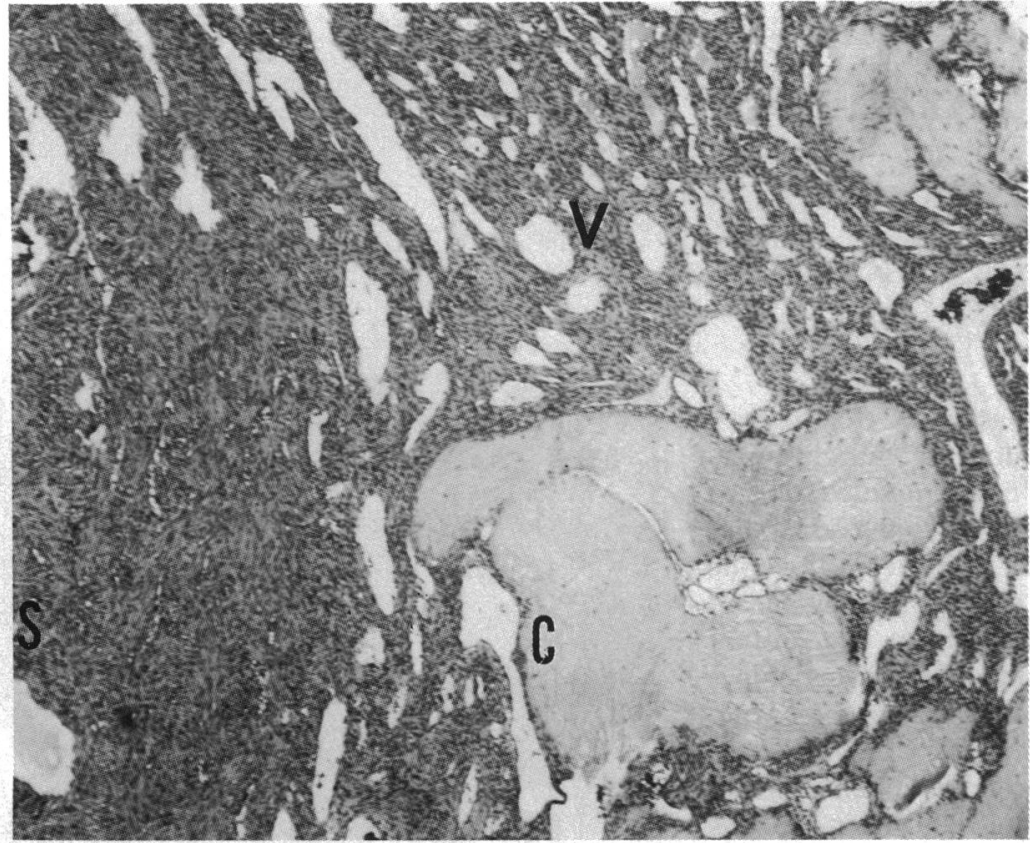

Figure 4 Cellularity varies from area to area. Solid spindle cells $(S)$, vascular component $(V)$, and dense collagen $(C)$. (Haematoxylin-eosin, $\times 160$.)

and without diastase digestion, Masson trichrome, Movat pentachrome, Wilder reticulin, Mallory's phosphotungstic acid-haematoxylin, Bodian, and alcian blue.

Sections from different parts of the tumour showed variation of cellularity from area to area (Fig 4). Dense collagenous strands were present in one area; in others an admixture of spindle cells and plump fusiform cells arranged in ribbons, fascicles, and bundles was present (Fig 5). Mitotic figures were rare. Small numbers of mononuclear cells were dispersed throughout, and giant cells were randomly scattered within some of the densely cellular areas. These cells were thought to eventuate from the previous operation. Vessels were most abundant in the

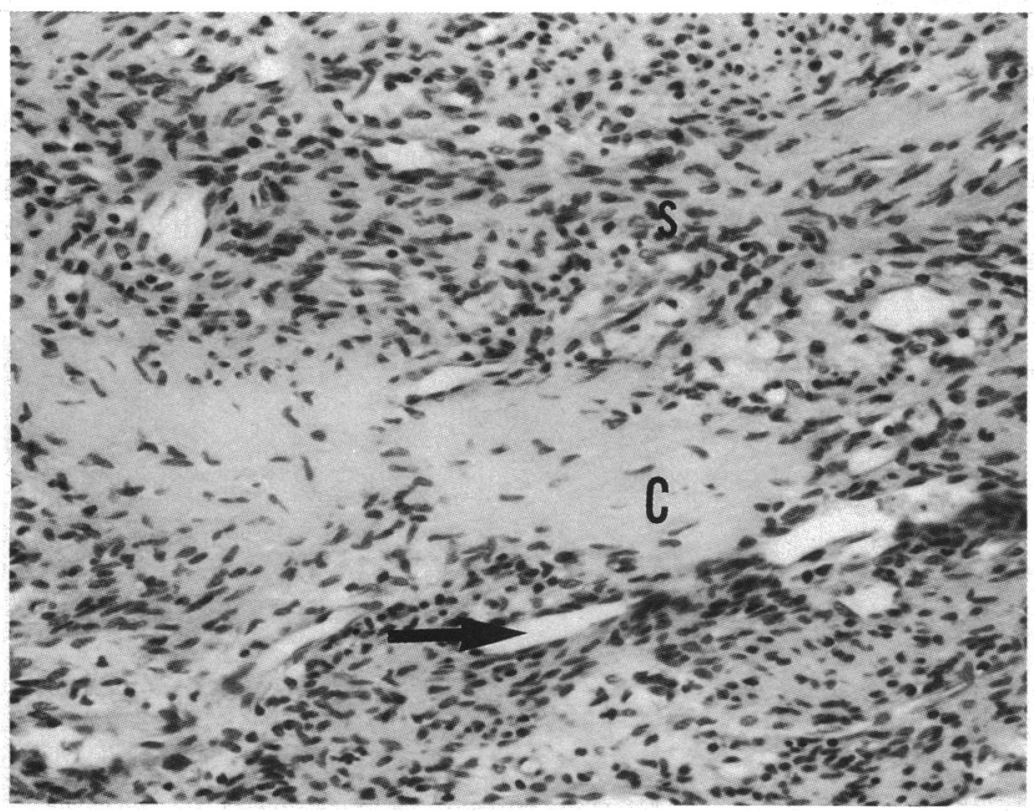

Figure 5 Spindle cells $(S)$ intertwine. Collagen $(C)$ is surrounded by slit-like vascular channels (arrow). (Haematoxylin-eosin, $\times 400$.) central portion of the tumour and varied from slit-like cavities (Fig 6) and capillary channels to cavernous spaces.

The special stains confirmed that the spindle cells were fibroblasts.

Electron microscopy showed great variability of the cells from one area to another, but the fibroblast, in various degrees of differentiation, predominated (Fig 7). Many fibroblasts showed irregular dilatation of the rough-surfaced endoplasmic reticulum and fine microfilaments (Fig 8). Macrophages with membrane-bound lysosomal structures within the cytoplasm were present.

\section{Discussion}

The group of fibromatoses has been defined as consisting of non-metastasising fibrous tumours that invade locally and recur after surgical excision. ${ }^{12}$ On occasion they may regress spontaneously. ${ }^{3-7}$ Most commonly they present in early childhood and young adulthood. The histological features of those that occur in children often differ markedly from those in adults ${ }^{8}$ and do not always correspond with the clinical behaviour. ${ }^{389}$

Stout ${ }^{2}$ used the term 'juvenile fibromatosis' to include a number of entities. One of these, congenital generalised fibromatosis, has been described under various names, including diffuse congenital fibromatosis. ${ }^{10}$ The many names used reflect the histogenic hypotheses in addition to the histological picture. The term 'fibromatosis' without qualification has been used for fibrous growths that could not be included in these categories. ${ }^{11}$

The subgroup of juvenile fibromatoses, namely 'congenital generalised fibromatosis,' is further subdivided ${ }^{1213}$ into (1) a solitary form; (2) a multicentric form in which the fibrous proliferation is restricted to subcutaneous tissues, skeletal muscle, and the ends of long bones; and (3) a generalised form with visceral involvement in addition to the features of the multicentric form. ${ }^{3}$ The solitary form is the more common. ${ }^{610^{14-16}}$ In one study, ${ }^{10} 73.8 \%$ of tumours were solitary, and the term 'myofibromatosis' was used because of the histological resemblance to smooth muscle tissue. The tumour showed a preference for the head and upper part of the body, including the arm. ${ }^{61011}$ However, only a few patients with ocular adnexal involvement have been described. ${ }^{1317-21}$

A female infant with congenital generalised fibromatosis and a large right infiltrating orbital tumour has been described. ${ }^{21}$ This mass also showed variation in cellular density, with marked vascularity in the peripheral areas. In a study of six children' five had involvement of the inferior orbital rim, with tumour extension into the lower lid in one patient. A solitary tumour localised to the zygomatic bone has been reported in a 3-month-old infant. ${ }^{20}$ All these solitary lesions ${ }^{1020}$ were managed by local excision.

Bilateral orbital involvement has been described in a 5-month-old boy with the congenital multicentric form of the disease. ${ }^{18}$ Fibromatosis of the cornea and limbus in association with 


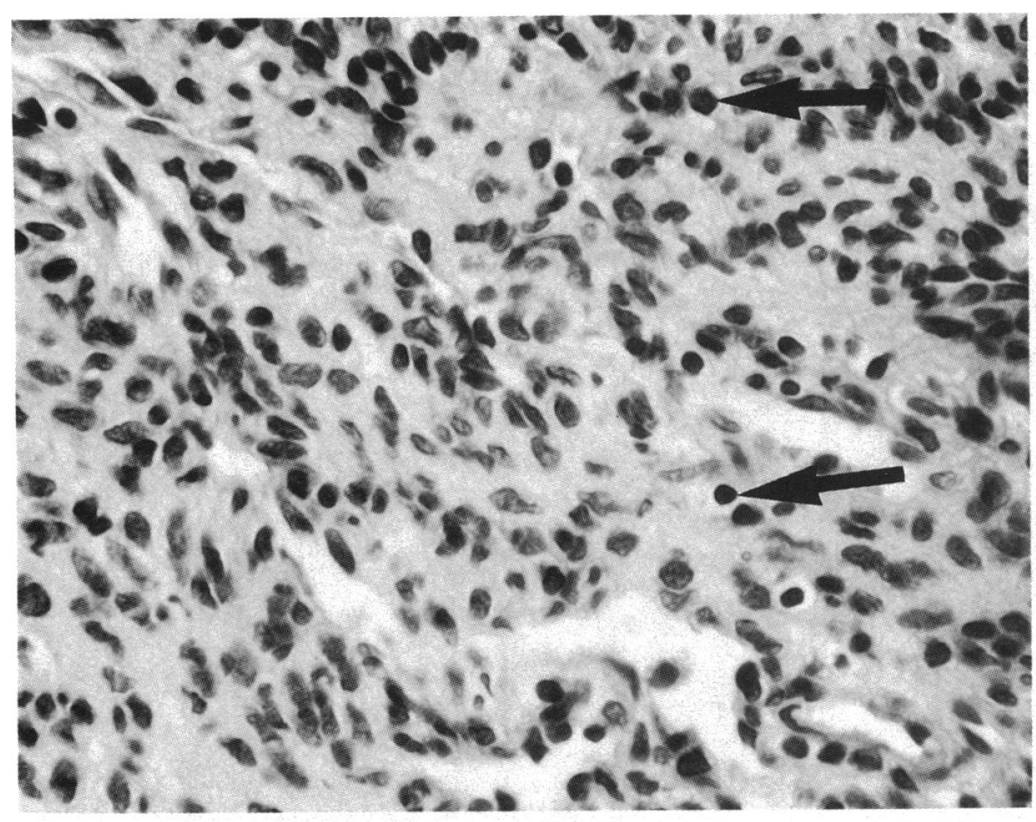

Figure 6 Central portion of tumour with spindle cells, sparse mononuclear cells (arrows), and slit-like vessels. (Haematoxylin-eosin, $\times 630$.

congenital generalised fibromatosis has also been reported. ${ }^{17} 19$

The solitary lesion averages $3 \mathrm{~cm}$ in diameter, is of slow growth, and has circumscribed or infiltrating edges. ${ }^{1361022}$ The histological features of the solitary and generalised forms are similar. ${ }^{616}$ Within an individual tumour the histological picture may vary from one field to another. ${ }^{1-3610}$ For this reason needle biopsy, frozen section, ${ }^{123}$ or even incisional biopsy are inadequate and may even be misleading (Fig 4).
This variation in pattern is a characteristic. Areas composed of densely cellular spindle-shaped cells coexist with areas that are heavily vascularised, and necrotic foci may be present. ${ }^{10}$ The microscopic picture may be confused with that of other mesenchymal neoplasms.

Electron microscopic studies of solitary tumours of orbital tissue ${ }^{12}$ and bone ${ }^{15}$ have shown that the basic tumour cell is the fibroblast in various stages of differentiation. Our studies support this finding and emphasise the wide variability from one portion of the tumour to another. Several authors have described smoothmuscle-like filaments. ${ }^{510}$

The pathogenesis of the tumour remains unclear. Trauma is considered to be coincidental. Although familial cases have been reported in congenital generalised fibromatosis, ${ }^{4102425}$ none have been reported thus far in patients with ocular adnexal tumours.

In conclusion, solitary form of fibromatosis, though benign, may recur; local excision with clear margins is recommended. The diagnosis may be made by examination of several sections from different parts of the tumour. Indeed, incisional biopsy may be misleading. The combination of features suggestive of haemangiopericytoma, leiomyoma, and neurofibroma aids in the diagnosis. The variability of the cellular component as seen by light and electron microscopy emphasises the wide range of differentiation of the fibroblast. Fibromatosis may be regarded as a disease process of wide spectrum. The prognosis for the solitary form is good.

This paper was presented at the Verhoeff Society, Boston, on 13-15 April 1989.

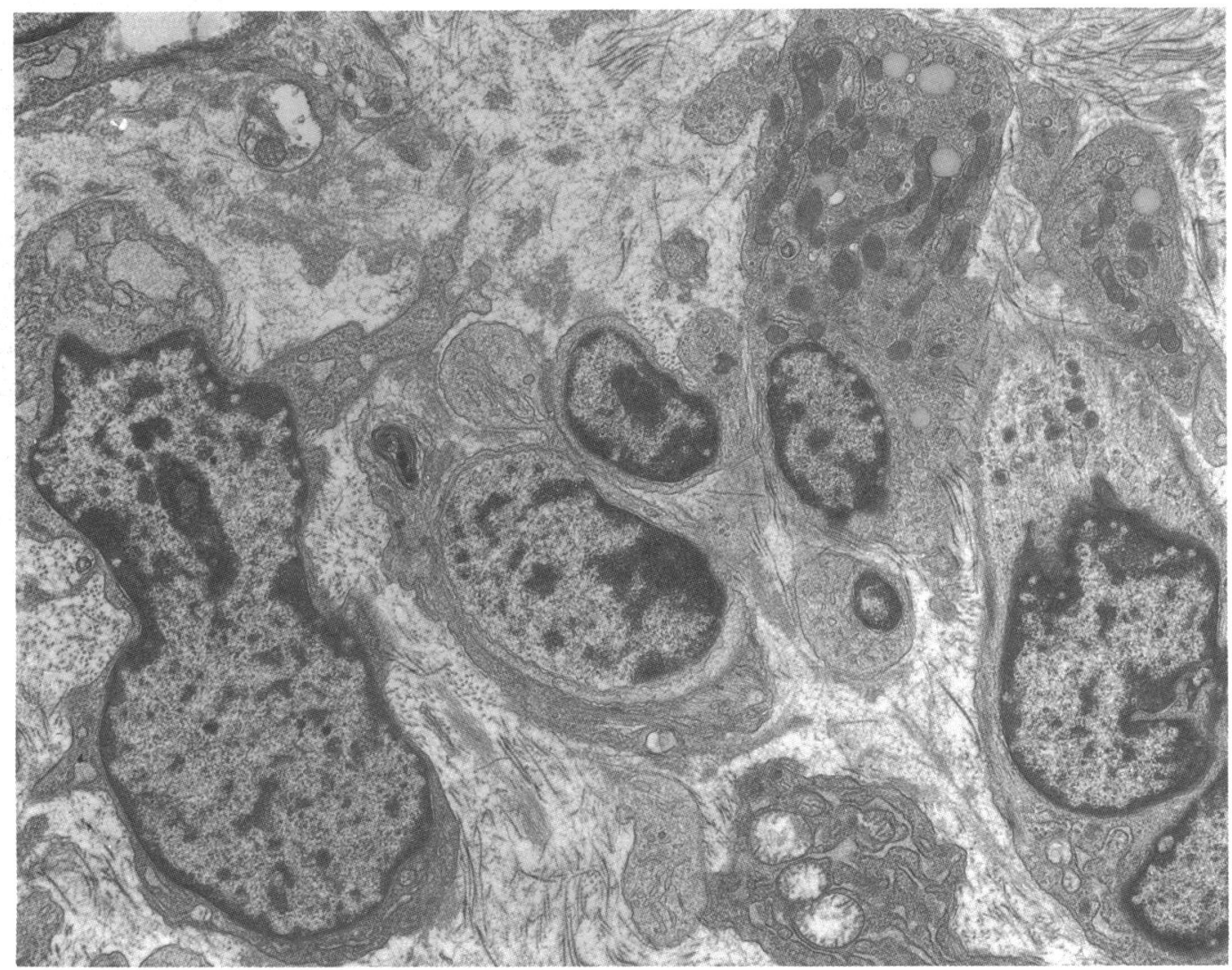

Figure 7 Electron micrograph showing fibroblasts in various degrees of differentiation. $(\times 17500$. 


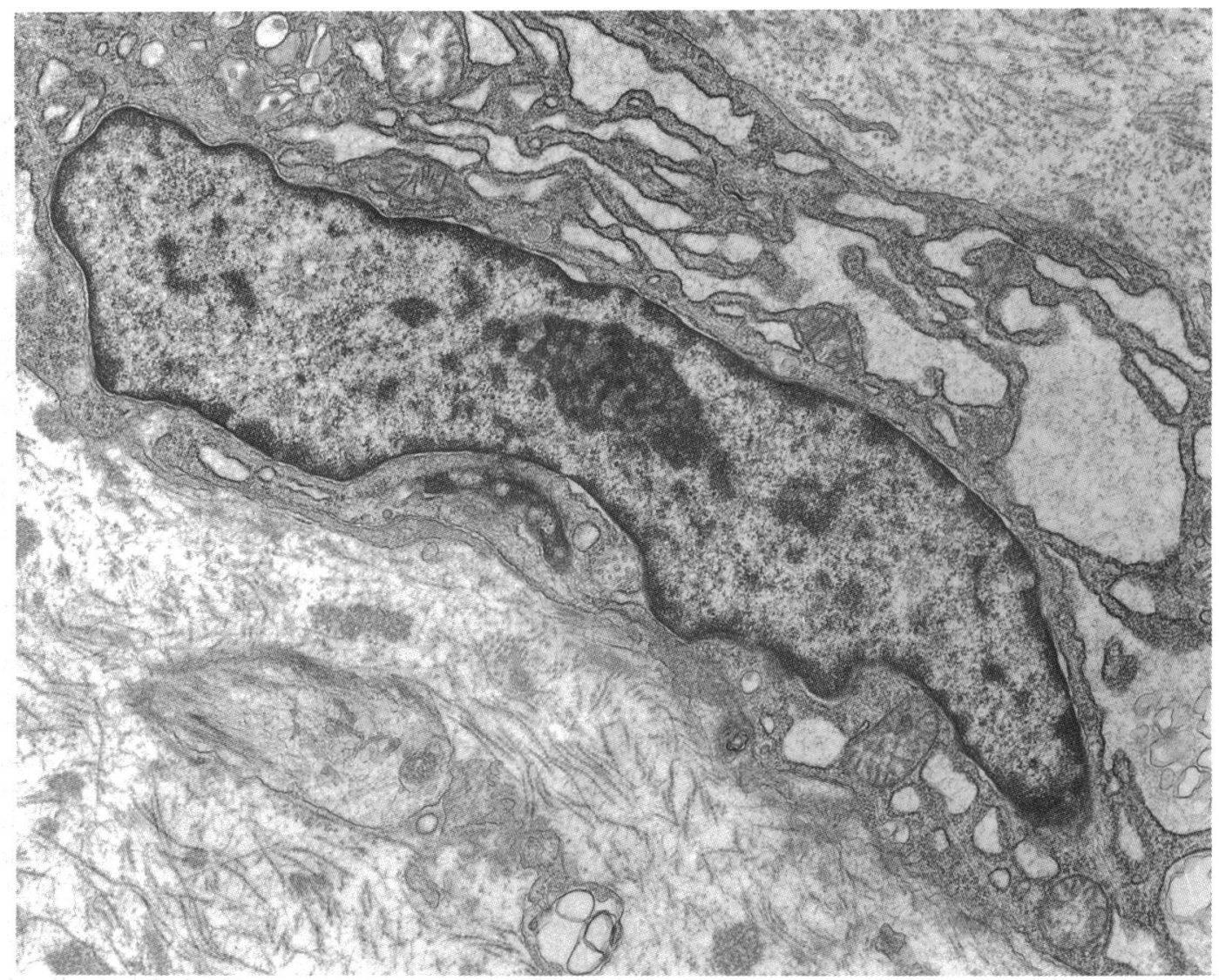

Figure 8 Electron micrograph showing fibroblast with distended, rough-surfaced endoplasmic reticulum. $(\times 37500$.

1 Hidayat AA, Font RL. Juvenile fibromatosis of the periorbital region and eyelid: a clinicopatholgic study of six cases. Arch Ophthalmol 1980; 98: 280-5.

2 Stout AP. Juvenile fibromatoses. Cancer 1954; 7: 953-78.

3 Baer JW, Radkowski MA. Congenital multiple fibromatosis: a case report with review of the world literature. AFR 1973; 118: $200-5$.

4 Baird PA, Worth AJ. Congenital generalized fibromatosis: an autosomal recessive condition? Clin Genet 1976; 9: 488-94.

5 Benjamin SP, Mercer RD, Hawk WA. Myofibroblastic contraction in spontaneous regression of multiple congenital traction in spontaneous regression of multiple congent
mesenchymal hamartomas. Cancer 1977; 40: 2343-52.

6 Briselli MF, Soule EH, Gilchrist GS. Congenital fibromatosis: report of 18 cases of solitary and 4 cases of multiple tumors. Mayo Clin Proc 1980, 55:554-62.

7 Schaffzin EA, Chung SMK, Kaye R. Congenital generalized fibromatosis with complete spontaneous regression: a case report. F Bone foint Surg $(A)$ 1972; 54: 657-62.

8 Stout AP. Fibrosarcoma in infants and children. Cancer 1962 15: $1028-40$.

9 Chung EB, Enzinger FM. Infantile fibrosarcoma. Cancer 1976; 38: 729-39.

10 Chung EB, Enzinger FM. Infantile myofibromatosis. Cancer 1981 ; 48: 1807-18.

11 Conley J, Stout AP, Healey WV. Clinicopathologic analysis of eighty-four patients with an original diagnosis of fibrosarcoma of the head and neck. Am F Surg 1967; 114: 564-9.

12 Kauffman SL, Stout AP. Congenital mesenchymal tumors. Cancer 1965; 18: 460-76.

13 Morettin LB, Mueller E, Schreiber M. Generalized hamartomatosis (congenital generalized fibromatosis). $A \mathcal{F} R 1972$ 114: $722-34$
14 Chung EB. Pitfalls in diagnosing benign soft tissue tumors in infancy and childhood. Pathol Annu 1985; 20: 324-5.

15 Kindblom L-G, Angervall L. Congenital solitary fibromatosis of the skeleton: case report of a variant of congenita generalized fibromatosis. Cancer 1978; 41: 636-40.

16 Kindblom L-G, Termén G, Säve-Söderbergh J, Angervall L. Congenital solitary fibromatosis of soft tissues, a variant of congenital generalized fibromatosis: two case reports. Acta Pathol Microbiol Scand Sect A 1977; 85: 640-8.

17 Antine BE, Brown FM, Arisco MI. Fibroma of the cornea report of a case associated with congenital generalized report of a case associated with congenital

18 Nasr AM, Blodi FC, Lindahl S, Jinkins J. Congenita generalized multicentric myofibromatosis with orbital in volvement. Am f Ophthalmol 1986; 102: 779-87.

19 Reese AB. Tumors of the eye. 3rd ed. New York: Harper and Row, 1976; 315-6.

20 Reich RH. Die lokalisierte kongenitale Fibromatose-ein Beitrag zur differentialdiagnose maligner Tumoren in Kindesalter. Dtsch Zahnärztl Z 1981; 36: 729-31.

21 Shnitka TK, Asp DM, Horner RH. Congenital generalized fibromatosis. Cancer 1958; 11 : 627-39.

22 Stout AP. The fibromatoses. Clin Orthop 1961; 19: 11-7.

23 Richardson WR, Dewar JP. Problems in managing fibrous tissue tumors in infants and children. Surgery 1964; 56 tissue the 36.

24 Bartlett RC, Otis RD, Laakso AO. Multiple congenital neoplasms of soft tissues. Report of 4 cases in 1 family. Cancer 1961; 14: 913-20.

25 Silberstein MJ, Brodeur AE, Graviss ER, Sundaram M. Diagnosis: congenital generalized fibromatosis. Orthopedics 1983; 6: 456-70. 